\title{
Washoff model of total suspended particles in urban areas
}

\author{
E. Crobeddu, S. Allali \& S. Bennis \\ Département de génie de construction, École de technologie supérieure, \\ Canada
}

\begin{abstract}
Urban runoff pollution due to suspended particles is of great concern for sewer system managers. This paper presents a new conceptual model called RQSM (Runoff Quality System Model) used to simulate the washoff (erosion and transport of particle) of total suspended particles (TSS) at the outlet of urban catchments. The RQSM model was validated with the help of 285 TSS data points monitored during 22 rainfall events. Four rainfall events were monitored in the subcatchment (1) of Verdun borough in Canada and 18 rainfall events were monitored on three subcatchments in Champaign city (USA). The simulated loads of the RQSM model were compared to the simulated loads obtained with the "rating curve" model and with the SWMM exponential washoff model. The performance criteria showed that the results given by the RQSM model are equivalent to the results given by the rating curve model and the SWMM exponential washoff model. A sensitivity analysis that was conducted on the RQSM model places of interest the influence of every parameter on the simulated loads.
\end{abstract}

Keywords: urban catchment, total suspended particles, build-up, washoff, comparative study.

\section{Introduction}

One of the municipality's interests is minimising the impact due to the pollution of stormwater in the natural environment. For real-time management of sewers network, the knowledge of the pollutograph associated to a rainfall event appears necessary to maximize the interception of pollutants. The estimation of the quantities of washoff suspended solids in the outlet of catchment allows 
estimating the level of runoff pollutions [11]. The cycle of the solid particles on an urban catchment is a complicated process; it consists of a stage of accumulation of the solid particles on the catchment in period of dry time and a stage of washing of the solid particles in times of rainoff. The erosion of soils in urban environment is a complex phenomenon and difficult to apprehend which was principally modeled with the aid of conceptual approaches. The simplest conceptual model "rating curve", the exponential model of software, the washoff model software of STORM, the washoff model of software HSPF, the model developed for the software HORUS, are models which introduce advantages to represent the physical phenomena implicated in the soil leaching. On the other hand, they use data which are rarely available or costly to acquire. The loads of suspended solids can also be calculated with the aid of statistical models [6]. Unfortunately, these models are only valid for sites where they were developed [7]. The "rating curve" model uses the runoff like the only explanatory variable of the erosion phenomena. The model of exponential washoff is used on the SWMM software; it takes into consideration the accumulated mass of solid particles.

This paper presents a new conceptual washoff model of the TSS in urban systems. The offered model will be validated with the aid of measurements of TSS performed on field. The results of the offered model will be compared with the results of exponential model and the model of "rating curve".

Moreover, the parameters of the offered model will be the object of an analysis of sensitivity.

\section{Formulation of RQSM model}

\subsection{Erosion of solid particles model}

The erosion process is related to the rainfall kinetic energy [12]. The following equation presents the kinetic energy of the precipitation $\mathrm{KE}\left(\mathrm{J} \cdot \mathrm{m}^{-2} \mathrm{~h}^{-1}\right)$ according to the uniform intensity of the rain $\mathrm{I}(\mathrm{mm} / \mathrm{h})[10]$ :

$$
K E(t)=\alpha I(t)^{\beta}
$$

where $\alpha$ and $\beta$, parameters related to macroscopic process formation of the drops of rain. The infinite accumulation hypothesis conducts to express the erosion rate $m p_{\text {imp }}\left(\mathrm{kg} \cdot \mathrm{m}^{-2} \cdot \mathrm{s}^{-1}\right)$ per the unit of impervious area by the following equation:

$$
m p_{\text {imp }}(t)=\frac{\alpha K p_{\text {imp }}}{3600} I(t)^{\beta}
$$

where $\mathrm{Kp}_{\text {imp }}$, the coefficient of the erosion per unit of impervious areas $(\mathrm{kg} / \mathrm{J})$. The erosion rate per unit of pervious areas $m p_{\text {per }}\left(\mathrm{kg} \cdot \mathrm{m}^{-2} \cdot \mathrm{s}^{-1}\right)$ starts when the rainfall intensity is above to the capacity of infiltration; it is given by the following equation:

$$
m p_{p e r}(t)=\frac{\alpha K p_{p e r}}{3600}[I(t)-f(t)]^{\beta}
$$


where $K p_{\text {per }}$, the coefficient of the erosion per unit of pervious areas $(\mathrm{kg} / \mathrm{J}) ; \mathrm{f}$, the capacity of infiltration of pervious areas $(\mathrm{mm} / \mathrm{h})$. The erosion rate $\mathrm{mp}_{\text {per }}$ given by the equation (3) is null when $\mathrm{f}(\mathrm{t}) \geq \mathrm{I}(\mathrm{t})$.

\subsection{Transport model of the solids particles}

By using the linear system theory [2], the transport model, with TSS concentration $\mathrm{C}\left(\mathrm{kg} \cdot \mathrm{m}^{-3}\right)$, on the depth runoff is given by the following equation:

$$
m l(t)=\int_{0}^{t} I_{n e t}(\tau) C(\tau) u(t-\tau) d \tau
$$

where $\mathrm{ml}$ represents the load of suspended particles $(\mathrm{kg} / \mathrm{s})$; moreover the equation (4) can be rewritten as follows:

$$
m l(t)=\int_{0}^{t} m p(\tau) C(\tau) u(t-\tau) d \tau
$$

where $\mathrm{mp}$ is the erosion rate of suspended particles per unit of area $\left(\mathrm{kg} \cdot \mathrm{m}^{-2} \cdot \mathrm{s}^{-1}\right)$. Depth precipitations are generally measured in step of variable time. Then they were sampled in constant time's steps and transformed into intensities. By choosing a step of time of unit sampling of 1 minute length, the convolution product between the erosion rate per unit of area and the response of the catchment is given by the following equation:

$$
\begin{aligned}
& m l(n)=\sum_{i=1}^{n \leq n_{p}}\left[m p_{\text {imp }}(i) u_{\text {imp }}(n-i+1)\right] \\
& +\sum_{i=1}^{n \leq n_{p}}\left[m p_{\text {per }}(i) u_{p e r}(n-i+1)\right]
\end{aligned}
$$

For

$$
1 \leq(n-i+1) \leq t_{c}: \quad \mathrm{u}_{\mathrm{imp}}(\mathrm{n}-\mathrm{i}+1)=\frac{10000 I M P}{t_{c}} \mathrm{~A}
$$

And for

$$
1 \leq(n-i+1) \leq t_{c}: \quad \mathrm{u}_{\mathrm{per}}(\mathrm{n}-\mathrm{i}+1)=\frac{10000(1-I M P)}{t_{c}} \mathrm{~A}
$$

where $\mathrm{u}_{\mathrm{imp}} ; \mathrm{u}_{\mathrm{per}}$ represent impulse response of impervious and of pervious areas $\left(\mathrm{m}^{2} / \mathrm{min}\right)$ respectively ; A, the area of the catchment (ha); IMP, the fraction of impervious area directly drained; tc, the time of concentration of the catchment (min); $n$ and $i$, indices of time; $n_{p}$, the final indices of vector of the erosion rates per unit of area. Three comments to be made about the RQSM model. Firstly, the RQSM model dissociates the contribution of impervious and pervious areas. Secondly, this model uses only intensity of precipitations to describe the transport of TSS. Finally, the representatively of this model is related to the 
measure's precision of the precipitation intensity. Consequently, a resolution inferior or equal to five minutes is recommended for the measure of the precipitation intensity.

\section{Validation of RQSM model}

\subsection{The sites}

The RQSM, the "rating curve" and the exponential models were calibrated and validated with the help of 285 measures of TSS load. These measures were realized during four rainfall events [4] monitored in the subcatchment (1) of Verdun borough in Montréal (Canada) and 18 rainfall events [9] monitored on three subcatchments in Champaign city (USA). For those 22 rainfall events, the intensity and the flow at the outlet of catchments were monitored in a step of 5 minutes. The calculation of the kinetic energy of precipitations was realized by taking $\alpha$ equal to 11 and $\beta$ equal to 1,24 [10]. Moreover, the calculation of the infiltration capacity of impervious areas was realized by the aid of the Horton's model modified [3]. This model fluently used on urban system, takes into consideration the initial capacity of infiltration of the soil $\left(\mathrm{f}_{0}\right)$, of the final capacity $\left(\mathrm{f}_{\infty}\right)$ and of the temporal reduction of the infiltration capacity $(\mathrm{K})$.

Table 1 describes the physical characteristics of the used subcatchments. The areas, the slopes and the occupation of soil change sensibly form a catchment to other. The values of these physical characteristics were estimated by using a hydrologic model [5]. They can also be obtained by expressions or by tabulated values [2].

Table 1: $\quad$ Physical characteristics of the four urban subcatchments used in the RSQM validation.

\begin{tabular}{|l|l|c|c|c|c|c|c|c|}
\hline Catchments & $\begin{array}{l}\text { Occupation } \\
\text { of soils }\end{array}$ & A (ha) & IMP & $\begin{array}{c}\text { tc } \\
(\mathrm{min})\end{array}$ & $\begin{array}{c}\text { Slope } \\
(\mathrm{m} / \mathrm{m})\end{array}$ & $\begin{array}{c}\mathrm{f}_{0} \\
(\mathrm{~mm} / \mathrm{h})\end{array}$ & $\begin{array}{c}\mathrm{f}_{\infty} \\
(\mathrm{mm} / \mathrm{h})\end{array}$ & $\begin{array}{c}\mathrm{K} \\
\left(\mathrm{h}^{-1}\right)\end{array}$ \\
\hline Verdun & Residential & 177,0 & 0,39 & 37 & 0,005 & 85 & 25 & 2 \\
\hline Mattis North & Commercial & 6,8 & 0,58 & 30 & 0,004 & 200 & 33 & 2 \\
\hline Mattis South & Commercial & 11,2 & 0,40 & 18 & 0,010 & 200 & 33 & 2 \\
\hline Saint John North & Residential & 22,1 & 0,19 & 24 & 0,006 & 200 & 33 & 2 \\
\hline
\end{tabular}

\subsection{Calibration of the three washoff models}

The performance of such model of simulation can be evaluated by the aid of these three indicators: Coefficient of Nash, Mass ratio and the ratio of peak.

The precision of simulated washoff load is good as Nash is close to unit. In urban hydrology, a precise simulation of runoff flow conducts to a Nash superior to 0,8 . For the simulation of runoff quality, this coefficient can be lowered to 0,6 
because of several incertitude surround measurement of pollutants [1] and of the complexity of physical mechanisms to be modelled.

In the case of the subcatchment of Verdun, an event which the intensity did not exceed the capacity of infiltration of the impervious area was used to calibrate parameter $\mathrm{Kp}$ imp. Later, an event which the intensity exceeded the capacity of infiltration of the pervious area was used to calibrate parameter $\mathrm{Kp}_{\mathrm{per}}$. In fact, an event presenting a weak intensity does not saturate the soil of the pervious area. As a result, the erosion will only be at the impervious areas. On the other hand, an event presenting a strong intensity saturates the soil of the pervious area, thus generating the erosion of the pervious and impervious areas.

For the three subcatchments of the city of Champaign, rainfall events were not important enough to contribute to the pervious areas. As a result, just coefficient $\mathrm{Kp}_{\text {imp }}$ was calibrated.

Table 2 gives parameter values after the calibration of RQMS, "rating curve" and exponential models. These values bring two comments. Firstly, the accumulated mass $\mathrm{Ma}(0)$ of the exponential model and the coefficient of erosion $\mathrm{Kp}_{\mathrm{imp}}$ of the RQSM model do not seem to be correlated in the catchment's area or in the occupation of soil introduced in table 1. Secondly, the parameter $\mathrm{k}$ of the exponential model introduces strong variations between the different subcatchments. These variations are explained to a great extent by the use of a model of instantaneous accumulation. In fact, the parameters of models RQSM and "rating curve" have amplitude of variation less than the exponential model while they use a model of infinite accumulation.

Table 2: $\quad$ Parameter values after the calibration of the RQSM, rating curve and exponential models.

\begin{tabular}{|c|c|c|c|c|c|c|c|}
\hline & \multicolumn{2}{|c|}{ Rating Curve } & \multicolumn{3}{c|}{ Exponential } & \multicolumn{2}{c|}{ RQSM } \\
\hline Catchments & $\mathrm{a}$ & $\mathrm{b}$ & $\begin{array}{c}\mathrm{Ma}(0) \\
(\mathrm{kg})\end{array}$ & $\mathrm{k}$ & $\mathrm{r}$ & $\begin{array}{c}\mathrm{Kp}_{\text {imp }} \\
(\mathrm{kg} / \mathrm{j})\end{array}$ & $\begin{array}{c}\mathrm{Kp}_{\text {per }} \\
(\mathrm{kg} / \mathrm{j})\end{array}$ \\
\hline Verdun & $8,45.10^{-2}$ & 1,29 & 2963 & $9,89.10^{-2}$ & 1,14 & $7,66.10^{-6}$ & - \\
\hline Mattis North & 1,41 & 1,46 & 552 & 8,27 & 1,13 & $2,84.10^{-5}$ & - \\
\hline Mattis South & 1,05 & 1,44 & 100 & 38,54 & 1,36 & $7,57.10^{-6}$ & - \\
\hline $\begin{array}{c}\text { Saint John } \\
\text { North }\end{array}$ & 2,26 & 2,15 & 273 & 112,25 & 2,88 & $1,41.10^{-5}$ & - \\
\hline
\end{tabular}

\subsection{Comparison of the three models of washoff}

The pollutographs of TSS provided by RQSM, exponential and "rating curve" models were compared with the 11 measured pollutographs remaining. The value of the indicators of performance after simulation is provided in table 3 . The three models provided a pollutograph near to the pollutograph measured for $50 \%$ of the measured events. The RQSM model has modelled the mass of TSS washed in a way equivalent to the model of "rating curve" but better than the exponential model. The RQSM model has modelled the peak of the pollutograph 
in an equivalent means to the "rating curve" model but less although the exponential model.

Table 3: $\quad$ Performance criteria values from the simulation of particle leads with the RQSM, rating curve (RC) and exponential (EXP) models.

\begin{tabular}{|l|c|c|c|c|c|c|c|c|c|}
\hline \multirow{2}{*}{ Events } & \multicolumn{3}{|c|}{ Nash } & \multicolumn{3}{c|}{ RM } & \multicolumn{3}{c|}{ Rp } \\
\cline { 2 - 10 } & RC & EXP & RQSM & RC & EXP & RQSM & RC & EXP & RQSM \\
\hline V.30-09-99 & $-0,05$ & 0,48 & 0,25 & 0,71 & 0,99 & 0,66 & 0,51 & 0,55 & 0,56 \\
\hline V.13-10-99 & 0,49 & 0,06 & 0,70 & 0,85 & 1,36 & 0,98 & 0,74 & 1,16 & 1,02 \\
\hline $\begin{array}{l}\text { M.N } \\
\text { 17-05-80 }\end{array}$ & 0,81 & 0,85 & 0,46 & 1,23 & 1,44 & 0,79 & 0,87 & 1,03 & 0,64 \\
\hline $\begin{array}{l}\text { M.N. } \\
\text { 23-05-80 }\end{array}$ & $-2,39$ & 0,12 & 0,89 & 3,22 & 2,24 & 1,13 & 2,49 & 1,56 & 1,24 \\
\hline $\begin{array}{l}\text { M.N. } \\
01-06-80\end{array}$ & $-1,47$ & $-5,14$ & 0,42 & 2,80 & 3,02 & 1,54 & 1,75 & 2,26 & 0,99 \\
\hline $\begin{array}{l}\text { M.S. } \\
\text { 01-06-80 }\end{array}$ & $-0,22$ & 0,92 & 0,52 & 2,37 & 1,32 & 1,29 & 1,97 & 1,26 & 0,69 \\
\hline $\begin{array}{l}\text { M.S. } \\
\text { 23-06-80 }\end{array}$ & $-1,19$ & 0,51 & 0,88 & 2,31 & 0,63 & 0,99 & 2,34 & 1,02 & 0,90 \\
\hline $\begin{array}{l}\text { M.S. } \\
\text { 28-06-80 }\end{array}$ & 0,73 & 0,98 & $-0,07$ & 1,43 & 0,92 & 0,47 & 1,06 & 0,91 & 0,19 \\
\hline $\begin{array}{l}\text { S.J.N. } \\
\text { 17-05-80 }\end{array}$ & 0,88 & 0.80 & 0,65 & 0,76 & 0,58 & 1,50 & 0,95 & 0,86 & 1,21 \\
\hline $\begin{array}{l}\text { S.J.N. } \\
\text { 30-05-80 }\end{array}$ & 0,90 & 0,76 & 0,88 & 0,73 & 0,54 & 1,03 & 0,94 & 0,81 & 0,82 \\
\hline $\begin{array}{l}\text { S.J.N. } \\
01-06-80\end{array}$ & 0,88 & 0,79 & 0,26 & 0,89 & 0,83 & 1,48 & 1,09 & 1,20 & 0,66 \\
\hline
\end{tabular}

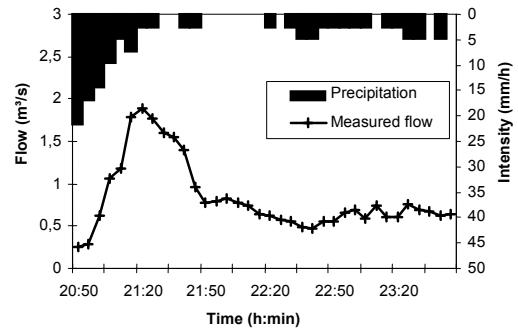

(a)

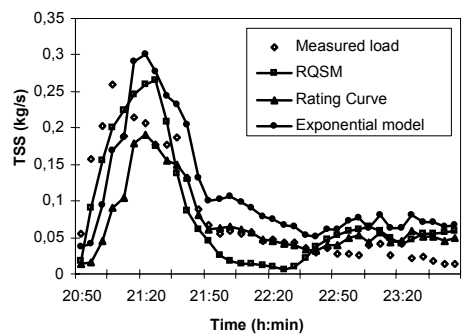

(b)

Figure 1: (a) Rainfall and flow in the subcatchment (1) of the Verdun borough on 13 October 2000, and (b) measured and simulated TSS loads. 
Figures 4 and 5 present two events simulated by RQSM, exponential and "rating curve" models. These two events show that the correlation between the hyetograph and the pollutograph is not essential to provide good results with the RQSM model. On the other hand, a good correlation between hydrograph and pollutograph allows the exponential and "rating curve" models to reproduce better the form of the pollutograph. Nevertheless, it is not synonymous with a good estimate of the load with TSS washed as shown in the figure 5 for the "rating curve" model.

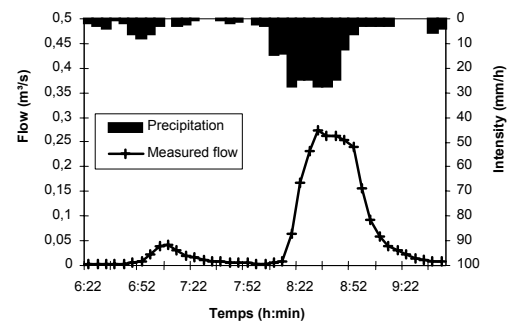

(a)

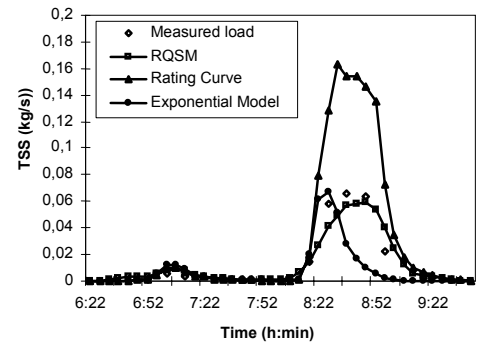

(b)

Figure 2: (a) Rainfall and flow in South Mattis on 23 June1980, and (b) measured and simulated TSS loads.

On the basis of these results, the comparison of the three models can be misleading since it masks the presence of disparities in the results. In order to have a vision more representative of the performance of RQSM, exponential and "rating curve" models, the mean value of the indicators of performance and their standard deviation are presented in table 4 which the values are the consequence of four sources of different uncertainties. The first comes from uncertainty associated with measurements of the precipitations, the rainfall flows, and especially with the loads of TSS [1]. The second results from the ignorance of the processes of accumulation of the solid particles on impermeable area during the period of dry time. The third comes from the absence of description of the processes of deposition and erosion of the solid particles during the phase of transport. Finally, the fourth source from the use of the models on the no uniforms subcatchments as regards roughness, of slope and distribution of the solid particles.

Table 4: $\quad$ Means and standard deviations of the Nash, Rp and RM.

\begin{tabular}{|c|c|c|c|c|c|c|}
\hline \multirow{2}{*}{ Models } & \multicolumn{2}{|c|}{ Nash } & \multicolumn{2}{c|}{ RM } & \multicolumn{2}{c|}{ Rp } \\
\cline { 2 - 7 } & Mean & $\begin{array}{c}\text { Standard } \\
\text { deviation }\end{array}$ & Mean & $\begin{array}{c}\text { Standard } \\
\text { deviation }\end{array}$ & Mean & $\begin{array}{c}\text { Standard } \\
\text { deviation }\end{array}$ \\
\hline Rating Curve & $-0,06$ & 1,14 & 1,57 & 0,93 & 1,34 & 0,68 \\
\hline Exponential & 0,33 & 0,93 & 1,26 & 0,77 & 1,15 & 0,45 \\
\hline RQSM & 0,53 & 0,31 & 1,08 & 0,35 & 0,81 & 0,31 \\
\hline
\end{tabular}




\subsection{The sensitivity analysis of RQSM model}

The analysis of sensitivity related to the parameters of calibration $\mathrm{Kp}_{\mathrm{imp}}$, $\mathrm{Kp}_{\mathrm{per}}$ and on the physical parameters $\mathrm{Tc}, \mathrm{f}_{0}, \mathrm{f}_{\infty}, \mathrm{K}$. In fact, the measured or calculated value of these four physical parameters is often surrounded by a great uncertainty. The sensitivity of these six parameters are evaluated by considering the coefficient of Nash. The reference values of these six investigated parameters are presented in table 5. They were used to calculate a pollutograph reference. Thereafter, a variation was imposed on one values of reference of RQSM model. The new pollutograph thus obtained was used with the pollutograph of reference in order to calculate the coefficient of corresponding Nash.

Table 5: $\quad$ Reference values of the parameters used for the sensitivity analysis of the RQSM model.

\begin{tabular}{|c|c|c|c|c|c|c|c|c|}
\hline Parameters & $\begin{array}{c}\mathrm{A} \\
(\mathrm{ha})\end{array}$ & $\mathrm{IMP}$ & $\begin{array}{c}\mathrm{tc} \\
(\mathrm{min})\end{array}$ & $\begin{array}{c}\mathrm{f}_{0} \\
(\mathrm{~mm} / \mathrm{h}\end{array}$ & $\begin{array}{c}\mathrm{f}_{\infty} \\
(\mathrm{mm} / \mathrm{h})\end{array}$ & $\begin{array}{c}\mathrm{K} \\
(1 / \mathrm{h}\end{array}$ & $\begin{array}{c}\mathrm{Kp}_{\text {imp }} \\
(\mathrm{kg} / \mathrm{j})\end{array}$ & $\begin{array}{c}\mathrm{Kp} p_{\text {per }} \\
(\mathrm{kg} / \mathrm{j})\end{array}$ \\
\hline Values & 100 & 0,5 & 32 & 160 & 16 & 4 & $2.10-5$ & $2.10-5$ \\
\hline
\end{tabular}

The analysis of sensitivity was conducted with aid the two following rains:

- $\operatorname{rain}(1): \mathrm{I}=10 \mathrm{~mm} / \mathrm{h}$; duration: $240 \mathrm{~min}$.

- $\operatorname{rain}(2): \mathrm{I}=80 \mathrm{~mm} / \mathrm{h}$; duration: $25 \mathrm{~min}$.

The rain (1) generates a height of water lower than the capacity of infiltration of pervious areas defined by the parameters of reference of the RQSM model. On the other hand, the rain (2) generates a height of water higher than the capacity of infiltration of pervious areas. By consequence, the rain (1) leaches only impervious areas whereas the rain (2) leaches pervious and impervious areas.

The results of the sensitivity analysis for the rain (1) are presented at figure 6(a). They bring two important remarks. Firstly, the variation of the $\mathrm{Kp}_{\text {imp }}$ parameter generates a strong increase of the coefficient of Nash. As result, $\mathrm{Kp}_{\mathrm{imp}}$ should be thoroughly calibrated. Finally, the variation of time of concentration generates a weak reduction of Nash. Consequently, an approximate value of tc can be used for the rains of low intensity and duration higher to tc.

The analytical results of the sensibility of rain (2) are presented in figure 6(b). They bring 4 important points. Firstly, the variation of the $\mathrm{Kp}_{\mathrm{imp}}$ parameter generates a higher increase in the coefficient of Nash like for the rain 1. On the other hand, the variation of the $\mathrm{Kp}_{\text {per }}$ parameter practically does not decrease Nash. Nevertheless, this parameter can become influential in the event of extreme rain or for a pervious area having a low capacity of infiltration. Secondly, when the duration of rain is higher than tc, the variation of tc generates a greater reduction of Nash than the variation of $\mathrm{Kp}_{\text {imp. }}$. On the other hand, when the duration of rain is less than tc, the influence of tc decreases significantly and becomes even lower than the variation of $\mathrm{Kp}_{\mathrm{imp}}$. Thirdly, an important variation of the initial capacity of infiltration $\left(f_{0}\right)$ generates an important drop of Nash. Moreover, the under-estimation of the initial capacity of infiltration generates a reduction of Nash more important than its overvaluation. 
Finally, the variation of the final capacity of infiltration $\left(\mathrm{f}_{\infty}\right)$ and the coefficient of reduction $(\mathrm{K})$ caused a negligible reduction of Nash. As a result, the variation of these parameters was not introduced in figure 6(b) to ease reading. These results of the infiltration parameters for the Horton model are similar to the observations given by the sensibility analysis of the non-linear model reservoir of SWMM software [8].

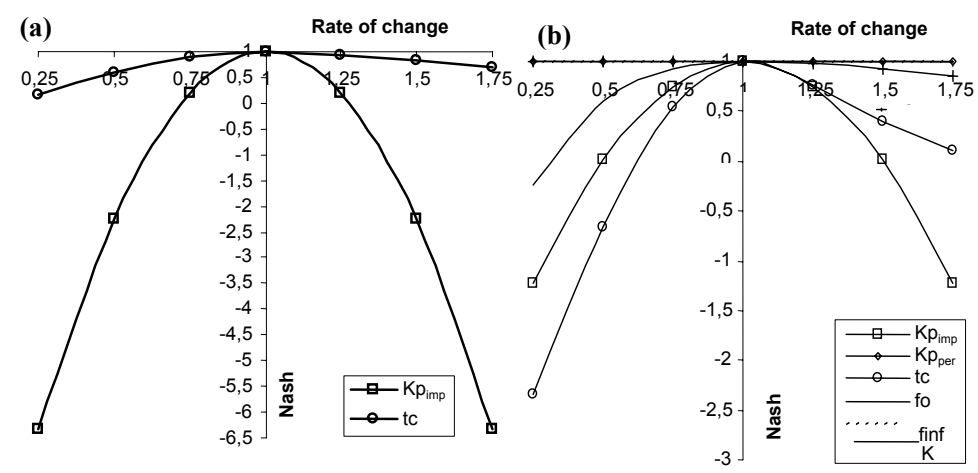

Figure 3: Variation of the Nash value as a function of the rate of change of the RQSM parameters for (a): rainfall (1), and (b): rainfall (2).

\section{Conclusion}

The present article places of interest an original conceptual approach to model the load of washoff of suspended solids on the urban catchments. The originality of the RQSM model results on the one hand, from the use of the kinetic of precipitations to simulate the erosion of solids particles, and on the other hand, the use of the linear systems theory to represent the TSS transport in the catchment's area. The RQSM model presents three points. Firstly, it uses only the intensity of precipitations to calculate the load of TSS washed off in the outlet of urban catchment. Secondly, it dissociates the contribution in TSS of the pervious and impervious areas. Finally, only two parameters of the RQSM model require a calibration.

The RQSM model has simulated the measured TSS, in the outlet of four urban subcatchments located in North America, with a precision level identical to the two proven conceptual models.

The analysis of sensitivity of the RQSM model showed that two parameters had a significant impact on the simulated pollutograph.

Encouraging results acquired with the RQSM model allow envisaging an extension of its application to other pollutants. 


\section{References}

[1] Bertrand-Krajewski, J.L., Laplace, D., Joannis, C. \& Chebbo, G., Mesures en hydrologie urbaine et assainissement, TEC et DOC (Éditeurs). Lavoisier, Paris, 793 p, 2000.

[2] Chow, V.T., Maidment, D.R. \& Mays, L.W., Applied hydrology. McGrawHill (Éditeur), 572 p, 1988.

[3] Huber, W.C. \& Dickinson, R.E., Storm Water Management Model, Version 4, User's Manual. U.S. EPA, EPA/600/3-88/001a., Athens, Georgia, 1988.

[4] Bennis, S., Caractérisation des eaux pluviales du secteur 1 de la ville de Verdun. Rapport technique: École de technologie supérieure, Ville de Verdun et BGH Planning, 2000.

[5] Bennis, S. \& Crobeddu, E., La méthode rationnelle généralisée. Vecteur Environ., 38, pp. 41-52, 2005.

[6] Driver, N.E. \& Troutman, B.M., Regression models for estimating urban storm-runoff quality and quantity in the United States. J. Hydrol. 109, pp. 221-236, 1989.

[7] Jewell, T.K. \& Adrian, D.D., Statistical analysis to derive improved stormwater quality models. J. Water Pollut.Contr. Fed., 54, pp. 489-499, 1978.

[8] Liong, S.Y.; Chan, W.T.; Lum, L.H.; Knowledge-based system for SWMM runoff component calibration. Journal of Water Resources Planning and Management, 117(5), 507-524, 1991.

[9] Noel, D.C., Terstriep, M.L. \& Chenoweth, C.A., Nationwide Urban Runoff Program:. Illinois State Water Survey, Department of Energy and Natural Resources, Champaign, Illinois, SWS Contract, Report 410-1, 1987.

[10] Salles, C., Poesen, J. \& Sempere-Torres, J., Kinetic energy of rain and its functional relationship with intensity. J. Hydrol., 257, pp. 256-270, 2002.

[11] Tsihrintzis, V.A. \& Hamid, R., Modeling and management of urban stormwater runoff quality: a review. Water Resource Manage, 11, pp. 137164, 1997.

[12] Young, R.A. \& Wersma, J.L., The role of rainfall impact in soil detachment and transport. Water Resource. Res., 9, pp. 1629-1636, 1973. 